\title{
Síndrome febril desconocido, alta probabilidad de brucelosis, reporte de caso
}

\author{
Juan Carlos González Quiñones ${ }^{1}$; María Alejandra Parra Bernal²
}

1 Médico Familiarista. MsC Epidemiología. Clínica Juan N. Corpas.

2 Estudiante de Décimo Semestre, Medicina, Fundación Universitaria Juan N. Corpas

Correspondencia: Correspondencia: María Alejandra Parra Bernal: mariaa-parra@ juanncorpas.edu.co

Como citar: González JC, Parra MA. Síndrome febril desconocido, alta probabilidad de brucelosis, reporte de caso. Revista Cuarzo 2017; 23(1): 39-44.

Recibido: 18 de febrero de 2017

Aceptado: 25 de mayo de 2017

Publicado: 30 de junio de 2017

Licencia creative commons (c) (i)

\section{Resumen}

La brucelosis, causada por la bacteria gram negativa Brucella spp, es una de las grandes imitadoras en el mundo de las enfermedades infecciosas, puede simular diversas enfermedades multisistémicas, exhibir un amplio polimorfismo clínico que frecuentemente lleva a la pérdida de diagnósticos y falla en el tratamiento, aumentando la tasa de complicaciones asociadas a la misma (1). Se considera la más común enfermedad zoonótica de distribución mundial, con más de 500000 nuevos casos notificados anualmente, con una prevalencia mayor a 1/100000 habitantes en zonas endémicas como el Mediterráneo, la península Arábiga, India, México, Centro y Sur América, en los que la infección es adquirida principalmente a través del contacto directo con animales infectados $(1,2)$. El reporte de caso muestra un paciente masculino con diagnóstico final de síndrome febril con alta probabilidad de brucelosis, con diagnósticos relacionado de pielonefritis derecha, orquiepididimitis izquierda, epididimitis derecha. Por medio de IgM, IgG y Antígenos febriles se diagnostica Brucella spp, por lo cual se indica manejo antibiótico con Doxiciclina con resolución total del cuadro. Sobresale la importancia de realizar una historia clínica completa en el ingreso del paciente, con énfasis en antecedentes labores.

PALABRAS CLAVE: brucelosis, orquitis, pielonefritis, pancitopenia, Brucella.

\section{Abstract \\ Syndrome febril unknown, high probability of brucellosis, case report}

Brucellosis, caused by the gram negative bacterium Brucella spp, is one of the great imitators in the world of infectious diseases, can simulate various multisystem diseases, exhibit a broad clinical poly- 
morphism that frequently leads to loss of diagnosis and treatment failure, increasing the rate of complications associated with it (1). It is considered the most common zoonotic disease worldwide, with more than 500,000 new cases reported annually, with a prevalence of more than 1/100000 inhabitants in endemic areas such as the Mediterranean, Arabian Peninsula, India, Mexico, Central and South America, in which infection is mainly acquired through direct contact with infected animals $(1,2)$. The case report shows a male patient with final diagnosis of febrile syndrome with high probability of brucellosis, with related diagnosis of right sided pyelonephritis rided, left epidedymo-orchitis, right sided epididymitis, by means of IgM, IgG and febrile antigens it is diagnosed brucella, for this reason is indicated antibiotic management with doxycycline with total resolution of the pathology. Stands out the importance of performing a complete clinical history on the patient's admission, with an emphasis on his work history.

KEYWORDS: Brucellosis, Orchitis, Pyelonephritis, Pancytopenia, Brucella.

\section{Introducción}

El síndrome febril de origen desconocido, considerado por fiebre superior a $38,3^{\circ} \mathrm{C}$ en varias ocasiones, durante al menos tres semanas y que posterior a una semana de estudio intrahospitalario tenga diagnóstico incierto, se caracteriza por no tener hallazgos claros en la historia clínica, examen físico, laboratorios y pruebas imagenológicas, según su etiología se divide en causas infecciosas (40\%), malignidades (20\%), enfermedades del tejido conectivo (15\%) y misceláneas $(25 \%)(3,4)$. En Latinoamérica los porcentajes aumentan por incumplimiento de recomendaciones y mala ejecución de la historia clínica.

Una de las causas menos probable son las infecciones, específicamente por brucelosis, patología de obligatoria notificación, la cual presenta una distribución mundial de 0,5 millones de casos notificados anualmente, muchos de estos en diferentes zonas de Latinoamérica (2). Colombia no es un representante de esta patología (5), presenta una baja tasa de notificación dado el inespecífico cuadro de la enfermedad. La prevalencia de la enfermedad se encontraba hasta el año 2012 entre 0,14 \% y 10,4 \%, siendo una infección poco ocurrente, lo que limita el conocimiento de su presentación (figura 1) (6). Ésta abarca un amplio espectro clínico, puede ser asintomática hasta mortal, el mecanismo de transmisión es por contacto directo (mucosas, auto inoculación de material infectado o vacuna cepa 19) o indirecto (ingestión de leche y productos lácteos sin pasteurizar infectados), el periodo de incubación para el ser humano abarca de cinco a tres meses, las principales manifestaciones son fiebre aguda en el 93\%, astenia en el 95\%, cefalea en el 81\%, otros síntomas constitucionales en el $65 \%$. La presentación más frecuente es dolor osteoarticular, específicamente en miembros inferiores, sin embargo, puede comprometer cualquier órgano $(3,7)$. La infección se diagnostica inicialmente sospechando el agente causal por la clínica del cuadro, además de resultados positivos obtenidos en rosa de Bengala el cual posee una alta sensibilidad y especificidad, IgM, IgG Elisa (8). A continuación, se reporta el caso de un paciente con Alta probabilidad de Síndrome febril de origen desconocido por brucelosis, para el desarrollo del caso se obtuvo consentimiento informado por parte del paciente, investigación clasificada sin riesgo según la resolución 8430 de 1993.

\section{Información del paciente}

Se presenta el caso clínico de un paciente masculino de 51 años de edad, procedente y residente de Chía, campesino y ganadero, quien presenta cuadro febril de 1 mes de evolución, el cual inicio con fiebre matinal de $39^{\circ} \mathrm{C}$ cuantificada continua, asociado a cefalea en región temporal, pulsátil. Se auto medicó con Acetaminofen 500 miligramos cada 6 horas presentando mejoría durante la duración de acción del medicamento (6 horas), luego de lo cual reincidía la fiebre. Asocia hematuria franca, olor fétido, dolor lumbar no irradiado y dolor pélvico tipo opresivo, irradiado a región testicular con aumento del diámetro del testículo izquierdo, dos veces su tamaño normal, con presencia de calor, rubor, edema y dolor local que impedía la marcha. Consulta a una clínica a los 8 días donde diagnostican IVU complicada y deciden dar manejo ambulatorio con cefalexina y nitrofurantoina (no recuerda la dosis) por 7 días, sin mejoría completa de la sintomatología. El paciente vuelve a consultar a los 10 días por exacerbación de los síntomas, persistencia de la fiebre, asocia náuseas, hiporexia y sensación de plenitud, donde remiten para hospitalización en Bogotá. 
A la revisión por sistemas se encuentra pérdida de $8 \mathrm{~kg}$ de peso en 2 meses, asociado a disminución en la ingesta. Como antecedente de importancia vive en una finca, trabaja con ganado. No se encontró otros datos importantes.

\section{Hallazgos clínicos}

$\mathrm{Al}$ examen físico de ingreso se encuentra en buenas condiciones generales, sin alteraciones de signos vitales, temperatura de $36,9^{\circ} \mathrm{C}$ en manejo con Acetaminofen 1 gramo cada 6 horas. Genital: Aumento del diámetro testicular izquierdo, signos de inflamación, doloroso a la movilización. Extremidades: miembros inferiores presencia de venas tortuosas y dilatadas. Columna: Puño percusión positiva. Paraclínicos de ingreso con resultados de: cuadro hemático con trombocitopenia de 53.000, leucocitos de 5.400, parcial de orina que reporta color naranja, deshidratación, hematuria.

\section{Evolución diagnóstica e intervención terapéutica}

En el primer día de hospitalización, al examen físico el paciente se encuentra en buenas condiciones generales, signos vitales normales, temperatura menor de $38{ }^{\circ} \mathrm{C}$, se encontró dolor a la palpación profunda en hemiabdomen inferior con persistencia de hallazgos anteriores. Paraclínicos primer día de hospitalización: PCR 12, Gram negativo.

Para su segundo día de hospitalización, persiste en buenas condiciones generales, con signos vitales normales. Se logra control de temperatura con acetaminofén (1 gramo cada 6 horas) y persisten hallazgos de ingreso. Asocia resultados de Cuadro hemático: leucocitos 4240 neutrófilos 51\%, hematocrito 39.3, trombocitopenia 21.000.

Al tercer día de hospitalización, el paciente asocia dolor a la palpación profunda en hemiabdomen inferior. Persisten hallazgos anteriores con temperatura controlada con acetaminofén igual dosis. Los paraclínicos reportan cuadro hemático: trombocitopenia 15.000 leucopenia 3.370 neutrófilos $47.2 \%$ hematocrito 37.5 y hemoglobina 12, Ultrasonografía de vías urinarias que reporta pielonefritis aguda derecha. Se indica tratamiento con Ampicilina Sulbactam 1.5 gramos cada 6 horas y acetaminofén 1 gramo cada 6 horas.

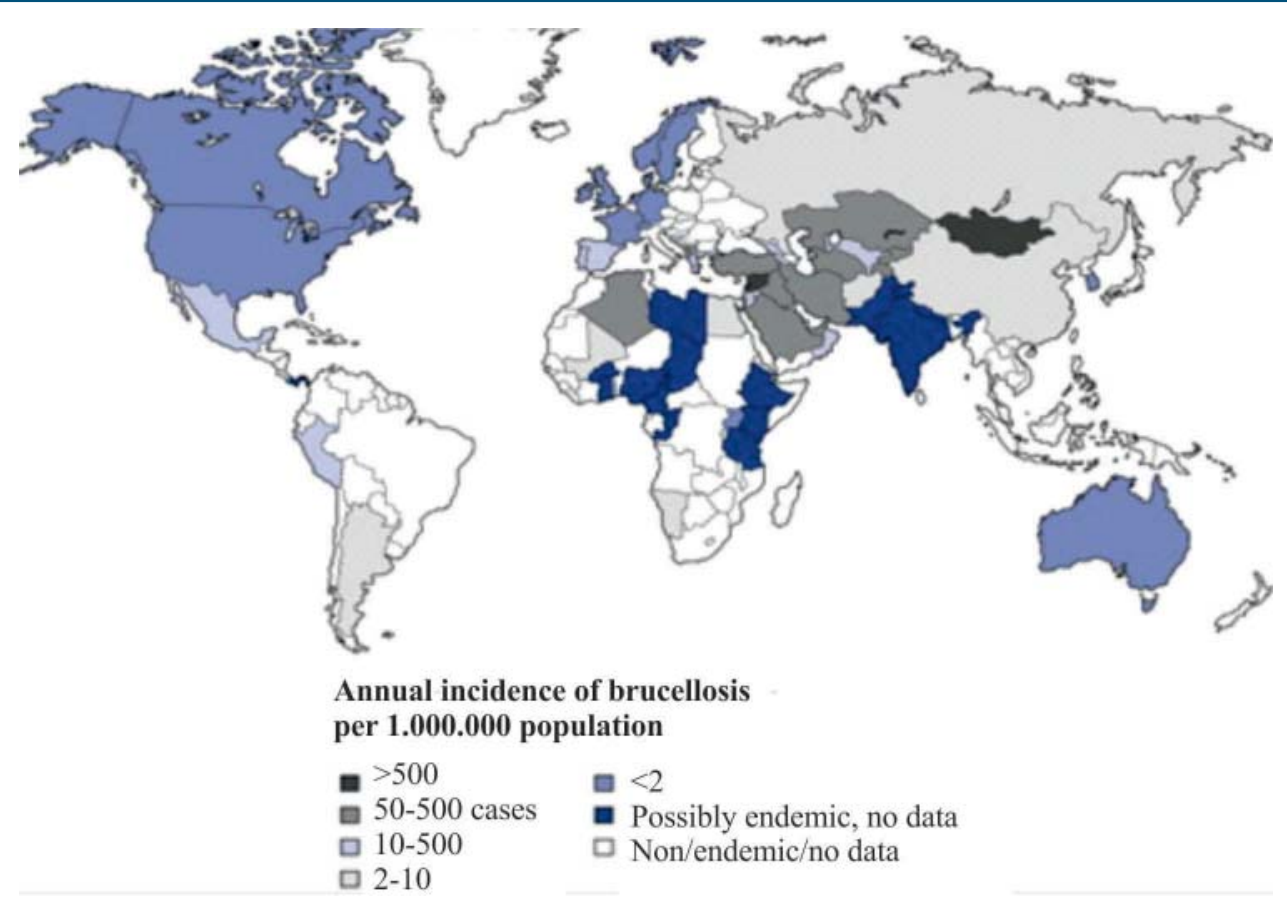

FIGURA 1. Reproduced from: Gutierrez Ruiz C, Miranda JJ, Pappas G (2006) A 26-year-old man with sternoclavicular arthritis. PLoS Med 3(8): e293 and derived from Ariza J, Bosilkovski M, Cascio A, et al. Perspectives for the treatment of brucellosis in the 21st century: the Ioannina recommendations. PLoS Med. 2007 Dec;4(12):e317 and Pappas G, Papadimitriou P, Akritidis N, Christou L, Tsianos EV (2006) The new global map of human brucellosis. Lancet Infect Dis 6:91-99. 
Durante el cuarto día de hospitalización el paciente no presenta cambios en su evolución clínica. Para el quinto día, al examen físico se encuentra disminución de la inflamación del testículo izquierdo. Asocia resultados de paraclínicos de Parcial de orina con hematuria microscópica, Creatinina normal, Cuadro hemático leucopenia 3390, trombocitopenia 16. 000. Se obtiene resultado de la Ecografía testicular que evidencia: epididimitis derecha, orquiepidimitis izquierda. Se asocia como diagnóstico: Síndrome febril de origen desconocido, Pielonefritis aguda derecha, Epididimitis derecha, orquiepidimitis izquierda, Aplasia medular interrogada e Insuficiencia venosa grado I.

En el sexto día de hospitalización, persiste la disminución de la inflamación de testículo izquierdo. Al examen físico, puño percusión negativa y se registra temperatura menor a $37^{\circ} \mathrm{C}$ sin Acetaminofén. Se continúa manejo antibiótico con Ampicilina Sulbactam. El paciente niega otros datos.

Al séptimo día de hospitalización no se encuentran nuevos hallazgos al examen físico. Los resultados de paraclínicos reportan cuadro hemático con leucopenia, tromobocitopenia 9.000 y anemia normocítica; serología no treponémica no reactiva; frotis de sangre periférica con disminución de líneas celulares. Se decide transfusión 6 UI plaquetas, se escalona antibiótico a ceftriaxona $1 \mathrm{gr}$ iv cada 12 horas (por epididimitis derecha y orquiepidimitis izquierda). Dado que en el cuadro hemático post transfusión persiste trombocitopenia 12.000, leucopenia 3050 y anemia, se decide realizar una nueva transfusión con 4UI de plaquetas y se asocia diagnóstico de pancitopenia (aplasia medular). El paciente no ha vuelto a presentar picos febriles sin acetaminofén.

Durante el octavo día de hospitalización, se observa al examen físico considerable mejoría de la inflamación del testículo izquierdo, llegando a resolución completa. Se registra nuevamente temperatura de $39^{\circ} \mathrm{C}$, por lo cual se reinicia acetaminofén. El resultado de hemograma post transfusión reporta plaquetas de 26.000. Al interrogatorio, el paciente quien refiere falta de recursos para vacunación de su ganado, por lo cual se solicita estudios para leptospira y brucelosis.

En el noveno día de hospitalización, el paciente presenta resolución del dolor abdominal, de la inflación testicular, sin puño percusión positiva, persiste la insuficiencia venosa grado I. SE reciben resultados de IgM para Lep-

\section{CALENDARIO}

FECHA 26/07/16

Temperatura de $36.9^{\circ} \mathrm{C}$
Tratamiento: Aceta-
minofén
minofén

$\begin{array}{ll} & \\ 27 / 07 / 16 & \begin{array}{l}\text { Temperatura menor } \\ \text { de } 38^{\circ} \mathrm{C}\end{array}\end{array}$

28/07/16

Temperatura controlada con Acetaminofén

29/07/16

\section{HALLAZGO S}

EXAMEN FÍSICO

Buenas condiciones generales, signos vitales normales Genital: Aumento del diámetro testicular izquierdo, signos de inflamación, doloroso a la movilización. Extremidades: miembros inferiores presencia de venas tortuosas y dilatadas.

Columna: Puño percusión positiva.

Buenas condiciones generales

Abdomen: dolor a la palpación profunda en hemiabdomen inferior con persistencia de hallazgos anteriores.

Buenas condiciones generales, signos vitales normales. Persistencia de hallazgos.

Se evidencia dolor a la palpación profunda en hemiabdomen inferior. Persisten hallazgos anteriores

\section{PARACLÍNICOS}

Cuadro hemático con trombocitopenia (53.000), leucocitos (5.400), parcial de orina que reporta color naranja, deshidratación, hematuria.

PCR 12, GRAM negativo.

Cuadro hemático: leucocitos 4240 neutrófilos 51\% hematocrito 39.3 trombocitopenia 21.000 .

Cuadro hemático: leucocitos 4240 neutrófilos 51\% hematocrito 39.3 trombocitopenia 21.000 . 


\begin{tabular}{|c|c|c|c|}
\hline $01 / 08 / 16$ & $\begin{array}{l}\text { Temperatura menor } \\
37^{\circ} \mathrm{c} \sin \text { Acetaminofén }\end{array}$ & $\begin{array}{l}\text { Genital: Disminución de la inflamación de testículo } \\
\text { izquierdo. Puño percusión: negativa. }\end{array}$ & \\
\hline $02 / 08 / 16$ & $\begin{array}{l}\text { No picos febriles sin } \\
\text { Acetaminofén. } \\
\text { INICIA: transfusión } \\
6 \text { UI plaquetas, Cef- } \\
\text { triaxona. Nueva trans- } \\
\text { fusión con } 4 \text { UI de } \\
\text { plaquetas. }\end{array}$ & Sin nuevos hallazgos al examen físico & $\begin{array}{l}\text { Cuadro hemático: leucopenia, tromobocito- } \\
\text { penia } 9.000 \text { y anemia normocítica } \\
\text { Serologíano treponémica no reactiva, Frotis } \\
\text { de sangre periférica: disminución de líneas } \\
\text { celulares. Cuadro hemático post transfu- } \\
\text { sión: trombocitopenia } 12.000 \text { leucopenia } \\
3050 \text { anemia. }\end{array}$ \\
\hline 03/08/16 & $\begin{array}{l}\text { Temperatura de } 39^{\circ} \mathrm{C} \text {, } \\
\text { se inicia acetaminofén. }\end{array}$ & $\begin{array}{l}\text { considerable mejoría de la inflamación del testículo } \\
\text { izquierdo hasta su resolución }\end{array}$ & $\begin{array}{l}\text { Hemograma post transfusión: plaquetas } \\
\text { de } 26.000 \text {. }\end{array}$ \\
\hline $04 / 08 / 16$ & $\begin{array}{l}\text { Temperatura dentro de } \\
\text { parámetros normales. } \\
\text { INICIA: Doxicicli- } \\
\text { na } 100 \text { mg } 12 \text { horas, } \\
\text { Acetaminofén solo si } \\
\text { presenta pico febril. }\end{array}$ & Extremidades: insuficiencia venosa grado I & $\begin{array}{l}\text { IGM para leptospira : negativo, IGM para } \\
\text { brucelosis: positivo, Antígenos febriles } \\
\text { positivos para brucella. }\end{array}$ \\
\hline 05/08/16 & $\begin{array}{l}\text { No presencia de picos } \\
\text { febriles }\end{array}$ & Examen físico sin nuevos hallazgos & $\begin{array}{l}\text { Cuadro hemático: plaquetas } 30.000 \text {, leuco- } \\
\text { citos } 3.325 \text {, anemia microcítica. }\end{array}$ \\
\hline
\end{tabular}

tospira spp, negativo; IgM para Brucella sp y antígenos febriles para Brucella spp, positivos. Se inicia manejo con Doxiciclina $100 \mathrm{mg} 12$ horas, Acetaminofén 1 gramo cada 6 horas, solo si presenta pico febril.

A lo largo del décimo día de hospitalización, no se asocian nuevos hallazgos al examen físico, el paciente refiere sentirse mejor y niega picos febriles en los últimos 2 días, niega sintomatología urinaria y tolera adecuadamente la vía oral, se realiza cuadro hemático que reporta plaquetas 30.000 , leucocitos 3.325 , anemia microcitica. Se decide dar egreso con Doxiciclina $100 \mathrm{mg}$ por 12 horas por 21 días, hemograma de control en 48 horas, recomendaciones generales, control por consulta externa (medicina familiar) en 4 días.

\section{Seguimiento y resultados}

El paciente consulta a los 2 meses sin ninguna sintomatología y habiendo finalizado el tratamiento.

\section{Discusión}

El diagnóstico principal del paciente fue fiebre de origen desconocido, teniendo en cuenta que previó a su ingreso hospitalario, presentó una duración mayor a tres semanas de un cuadro consistente en fiebre superior a 38.3 grados y posteriormente una estancia hospitalaria mayor a una semana. Dada su evolución, se dio salida con un posible diagnóstico final categorizado en el grupo de síndrome febril por enfermedad infecciosa con una prevalencia del $16 \%$ del diagnóstico general $(3,9)$. Ante esta categorización diagnóstica, se debe interrogar al paciente constantemente e indagar acerca de viajes recientes, exposición animal, por ejemplo, animales domésticos, ocupacionales, tipo de vivienda, inmunosupresión, historial de fármacos y toxinas, incluyendo antimicrobianos.

La infección por Brucella spp no es un diagnóstico común, tiene una incidencia de 500.000 casos al año y es causa poco frecuente del síndrome febril (1). Sin embargo, el antecedente de exposición con ganado aumenta la probabilidad de contraerla, es importante aclarar la sintomatología y relacionarla con la teoría. La bacteria ingresa a través de mucosas a los linfáticos llegando a la sangre venosa, transportada por neutrófilos y monocitos hasta el hígado, bazo, médula ósea, ganglios linfáticos y en general a cualquier órgano. En el caso de este paciente, el único hallazgo relacionado con el riesgo de esta patología, era el antecedente laboral de contacto con ganado infectado, lo cual lleva a considerar que la vía de ingreso fue directa. La triada de brucelosis es, trombocitopenia, leucopenia y linfocitosis, el cuadro clínico de la infección es difuso y solo se pueden atribuir a esta patología: cefalea fronto - occipital, que en el paciente era temporal 
no irradiada (10); fiebre, caracterizada por ser ondulante, intermitente y vespertina con picos entre $38.3^{\circ}$ y $40^{\circ}$, que en el paciente era continua, no intermitente; pérdida de peso lo cual refirió el paciente en un total de $8 \mathrm{~kg}$ de peso en 2 meses, aunque en el interrogatorio lo relaciono con disminución en la ingesta por inapetencia; diaforesis, asociada por el paciente con la fiebre como mecanismo de convección para liberar calor; orquiepididimitis localizada, infrecuente, prevalente en un 2- 14\% (9); sintomatología generalizada; escalofríos y falta de apetito. En la literatura se asignan más síntomas como: dolor abdominal, dolor lumbar, dolor articular, náuseas, fatiga, debilidad, inflamación de ganglios linfáticos, rigidez de nuca y dolor muscular (6).

La infección se diagnostica inicialmente con la sospecha clínica del cuadro además de resultados positivos obtenidos en la prueba de Rosa de Bengala que presenta una sensibilidad del 94\% y especificidad 100\%; Seroaglutinación estándar, Test de Coombs anti-Brucella, Reacción en Cadena de la Polimerasa e IgM, IgG con sensibilidad del 94\% y especificidad 96\%, ELISA C LPS con sensibilidad del 99\% y especificidad del 100\% (8,11,12). En el paciente se realizó IgM, IgG con antígenos febriles obteniéndose un resultado positivo, que en el contexto de sus antecedentes, resulta altamente sugestivo de un cuadro infeccioso febril asociado a Brucella spp cuyo tratamiento indicado es Doxicilina $100 \mathrm{mg}$ cada 12 horas durante 45 días (mínimo 6 semanas) más Estreptomicina 15 mg/kg IM al día durante 14-21 días o Gentamicina 3-5 mg/kg IV o IM al día durante 7-14 días; otra alternativa de manejo es Doxicilina 100 mg cada 12 horas durante 45 días más rifampicina 600-900 mg día durante 45 días (6,7). Dada la respuesta favorable del paciente, se da egreso hospitalario con Doxicilina 100 mg cada 12 horas durante 21 días.

Lo anterior nos permite observar que este tipo de cuadro infeccioso puede ser difuso y exige un enfoque acertado ya que su presentación varía dependiendo del paciente y requiere conocer detalladamente los antecedentes a fin de direccionar acertadamente el diagnóstico desde la primera intervención, disminuyendo los costos en hospitalización, mejorando la calidad y recuperación del paciente. La revisión de este caso pretendió mostrar una de las presentaciones de la infección por brúcela y su tórpida evolución y manejo al no aclarar desde un principio la importancia en la correlación de los antecedentes laborales como aspecto orientador en la aproximación diagnóstica de este tipo de enfermedades.

\section{Referencias}

1. Buzgan T, Kasim-Karahocagil M, Irmak H, Irfan-Barana, Karsen H, Evirgen O, et al. Clinical manifestations and complications in 1028 cases of brucellosis: a retrospective evaluation and review of the literature. International Journal of Infectious Diseases. 2010;14:469-478.

2. Bosilkovski M. Microbiology, epidemiology, and pathogenesis of Brucella [internet]. [Consultado 2017 septiembre 20]. Disponible en: https://www.uptodate.com/contents/ microbiology-epidemiology-and-pathogenesis-of-brucella

3. Pila-Pérez R, Pila-Peláez R, Guerra-Rodríguez C, Vázquez-Pérez L. Fiebre de origen desconocido. AMC. 2002;6(1):720-730.

4. Romo J, Muñoz J. Protocolo diagnóstico en fiebre de origen desconocido para países en vías de desarrollo. Anales de la Facultad de Medicina. 2004;65(2):127-132.

5. Instituto Nacional de Salud. Subdirección de vigilancia y control en salud pública Grupo Zoonosis. Informe final brucelosis humana datos retrospectivos en Colombia. 2009 [internet]. [Consultado 2017 agosto 23]. Disponible en: http://www.ins.gov.co/lineas-de-accion/SubdireccionVigilancia/Informe\%20de\%20Evento\%20Epidemiolgico/ Brucelosis\%20Humana\%202009.pdf

6. López-Guarnizo P. Estudio descriptivo de la presentación de brucelosis humana en Colombia desde 2000 hasta 2012. Rev. Med. Vet. 2014;28:67-79.

7. Segura-Luque J. Brucelosis. Southern Medical Journal. 2014;48(10):1135.

8. Nielsen KH, Kelly L, Gall D, Nicoletti P, Kelly W. Improved competitive enzyme immunoassay for the diagnosis of bovine brucellosis. Vet Immunol Immunopathol. 1995 Jun;46(3-4):285-291.

9. Alapont Alacreu J, Gómez López L, Delgado F, PalmeroMartí J, Pacheco Bru J, Pontones-Moreno J, et al. Brucellar orchiepididymitis. Actas urológicas españolas. 2004;28(10):774-776.

10. Ministerio de salud. Argentina. Brucelosis. Enfermedades infecciosas. Guía para el equipo de salud. 2013 [internet]. [Consultado 2017 septiembre 15]. Disponible en: http://www.msal.gob.ar/images/stories/bes/ graficos/0000000304cnt-guia-medica-brucelosis.pdf

11. Aranís J.C., Oporto J, Espinoza M, Riedel I, Pérez C, García P. Usefulness of the determination of IgG and IgM antibodies by ELISA and immunocapture in a clinical series of human brucellosis. Revista Chilena de Infectología. 2008;25(2):116-121.

12. Nielsen K, Yu WL. Serological diagnosis of brucelosis. Prilozi. 2010;31(1):65-89. 